\title{
AS NOVAS DIRETRIZES CURRICULARES NACIONAIS PARA FORMAÇÃO INICIAL E CONTINUADA DE PROFESSORES DA EDUCACCÃO BÁSICA: ENTRE RECORRÊNCIAS E NOVAS INQUIETAÇÕES
}

\author{
LAS NUEVAS DIRECTRICES CURRICULARES NACIONALES PARA LA FORMACIÓN \\ INICIAL Y CONTINUA DE LOS PROFESORES DE EDUCACIÓN BÁSICA: ENTRE \\ REPETICIONES Y NUEVAS ANSIEDADES
}

\section{THE NEW CURRICULUM GUIDELINES FOR NATIONAL INITIAL TRAINING AND CONTINUING EDUCATION TEACHERS OF THE BASIC: BETWEEN RECURRENCES AND NEW CONCERNS}

\author{
Mirtes Gonçalves HONÓRIO ${ }^{1}$ \\ Maria do Socorro Leal LOPES ${ }^{2}$ \\ Francisca Lourdes Santos LEAL ${ }^{3}$ \\ Teresa Christina Torres HONÓRIO ${ }^{4}$ \\ Vilmar Aires dos SANTOS ${ }^{5}$
}

RESUMO: O presente artigo resulta do esforço coletivo, a partir da produção de conhecimento, construído no Núcleo de Estudos Pesquisa e Extensão sobre Formação de Professores e Práticas Educativas - NEFORPE, da Universidade Federal do Piauí, no sentido de compreender, analisar e refletir acerca do que preconizam as novas diretrizes curriculares nacionais para a formação dos profissionais do magistério da educação básica e sobre os possíveis impactos decorrentes dessas diretrizes na institucionalização e nas práticas curriculares dos cursos de formação de professores, na direção de uma nova concepção de formação docente.

PALAVRAS-CHAVE: Política de formação de professores. Formação inicial. Formação continuada.

RESUMEN: Este artículo es el resultado del esfuerzo colectivo, de la producción de conocimiento, construido el núcleo de estudios e investigaciones sobre la formación de los docentes y las prácticas educativas-NEFORPE, de la Universidad Federal de Piauí, para

${ }^{1}$ Universidade Federal do Piaui (UFPI), PI - Brasil. Professora Adjunta do Departamento de Métodos e Técnicas de Ensino. E-mail: mirteshonorio@ @otmail.com

${ }^{2}$ Universidade Federal do Piaui (UFPI), PI - Brasil. Professora Adjunta do Departamento de Métodos e Técnicas de Ensino. Professora do Mestrado Nacional Profissional em Ensino de Física - MNPEF, Membro do Núcleo de Estudo Pesquisa e Extensão sobre formação de professores e práticas educativas-NEFORPE. Email: msleallopes@gmail.com

${ }^{3}$ Universidade Federal do Piaui (UFPI), PI - Brasil. Professora Adjunta do Departamento de Métodos e Técnicas de Ensino.

${ }^{4}$ Universidade Federal do Piaui (UFPI), PI - Brasil. Professora Assistente do Departamento de Métodos e Técnicas de Ensino.

${ }^{5}$ Universidade Federal do Piaui (UFPI), PI - Brasil. Professora Assistente do Departamento de Métodos e Técnicas de Ensino - UFPI. 
comprender, analizar y reflexionar sobre lo que defienden las nuevas directrices del currículo nacional para la formación de profesionales en las prácticas curriculares y enseñanza de la educación básica y en los posibles efectos de estas directrices sobre institucionalización docente de cursos de formación hacia una nueva concepción de la formación docente.

PALABRAS CLAVE: Política de formación docente. Formación inicial. Educación continua.

ABSTRAT: This article is the result of collective effort, from the production of knowledge, built in the Study Group Research and Extension on Teacher Training and Educational Practices - NEFORPE, the Federal University of Piaui, in order to understand, analyze and reflect on what advocate new national curriculum guidelines for the training of professionals in the basic education teaching and about the possible impacts of these guidelines in the institutionalization and in the curriculum practices of teacher training courses, towards a new conception of teacher education.

KEYWORDS: Teacher education policy. Initial formation. Continuing education.

\section{Ideias iniciais}

A aprovação das Diretrizes Curriculares Nacionais para a formação inicial em nível superior (cursos de licenciatura, cursos de formação pedagógica para graduados e cursos de segunda licenciatura) e para formação continuada, no dia $1^{\circ}$ de julho de 2015 , assinala um momento de transição para as políticas de formação dos profissionais do magistério da educação básica. Nessa data, completados 13 anos, revoga-se a Resolução CNE/CP 01/2002, que Institui Diretrizes Curriculares Nacionais para a Formação de Professores da Educação Básica, em nível superior, curso de licenciatura, de graduação plena e a Resolução CNE/CP 02/2002, que Institui a duração e a carga horária dos cursos de licenciatura, de graduação plena, de formação de professores da Educação Básica em nível superior.

A medida é apresentada em cumprimento à Meta $n^{\circ} 15$ do Plano Nacional de Educação (PNE) e entendida como necessária diante das diversas mudanças ocorridas na legislação relativa à formação de professores e às transformações em curso na própria sociedade, no mundo do trabalho e na formação de professores. O escopo do debate é 
amplo, assim como, o são as questões que permeiam a formação de professores no nosso país e suas respectivas políticas curriculares.

Diante dos múltiplos olhares e perspectivas, a partir das quais é possível analisar as atuais políticas para a formação de professores, pretende-se compreender o que as novas diretrizes trazem de novo para a formação dos profissionais do magistério da educação básica e analisar quais as novas possibilidades de organização dos cursos de formação de professores e que desafios continuam na agenda de debates.

Desse modo, a primeira parte do texto é dedicada à contextualização de algumas das principais mudanças pelas quais passou a formação de professores, especialmente em termos legais. A segunda, indica alguns dos aspectos introduzidos acerca da política de formação de professores, a partir das novas diretrizes curriculares nacionais para a formação inicial e continuada dos profissionais do magistério. E à guisa de considerações finais, tecemos proposições para se repensar o compromisso do Estado, das Instituições Formadoras e da escola.

\section{Recuperando alguns antecedentes legais}

Avanços e retrocessos têm demarcado a trajetória dos cursos de formação do profissional do magistério da educação básica. A descontinuidade deste processo sinaliza a interferência de fatores, tanto de natureza política, quanto de natureza cultural. Dentre eles podemos destacar a ausência de uma política de estado, que manifeste compromisso em garantir a necessária formação docente com a qualidade que demanda a sociedade contemporânea, assim como, o conflito institucional revelado, dentre outros indicadores, pela permanência do posicionamento dos acadêmicos em relação à natureza e o valor do conhecimento científico (BORDAS, 2008).

Após a promulgação da Lei de Diretrizes e Bases da Educação Nacional (LDB), instaura em nosso país uma nova proposta de formação de professores disciplinada por meio do Parecer CNE/CP 9/2001, que fundamenta as Resoluções CNE/CP 1/2002 e 2/2002, que definem as Diretrizes Curriculares Nacionais específicas aos cursos de licenciatura, trazendo ideias inovadoras acerca deste tema, visto que propuseram reflexões mais amplas do que as reformas anteriores.

Dentre tais reflexões a pesquisa como princípio educativo; 400 horas de prática como componente curricular, presente desde o início do curso permeando as disciplinas de 
formação, em uma perspectiva interdisciplinar deve ofecer ao futuro professor melhor compreensão do ambiente educacional e do contexto escolar, conforme o Parecer CNE/CP 28/2001; 400 horas de estágio, a partir da segunda metade do curso; além de contemplar 200 horas de atividades científicas e culturais em áres de interesses dos alunos, promovendo, assim, um processo de reconstrução das Licenciaturas. Essa imposição de 800 horas de atividades práticas foi o que mais provocou discussões nas instituições de ensino superior no momento de implementar os projetos pedagógicos a fim de atender essas determinações legais.

Assim, as Resoluções CNE/CP 01/2002 e 02/2002 propuseram um novo olhar sobre o formato dos cursos de Licenciatura, olhar esse favorecido pelo caráter de componente curricular atribuído às práticas. Como tal, as 400 horas de prática exigidas nos Projetos Pedagógicos, distribuídas ao longo dos anos de desenvolvimento do curso, devendo integrar-se com os demais componentes curriculares ou disciplinas. Percebe-se a ênfase, na prática como componente curricular, dos cursos de formação inicial de professores como oportunidade de refletir sobre o processo de formação inicial e auxiliar na constituição de uma identidade profissional necessária no contexto da sociedade contemporânea.

A definição de prática como "componente curricular" pressupõe uma perspectiva transversal, por via da integração teoria-prática com os demais componentes curriculares ou disciplinas. O parecer CNE/CP 9/2001 destaca a "concepção restrita de prática" dentre as questões a serem enfrentadas no campo curricular e explicita:

Uma concepção de prática mais como componente curricular implica vêla como uma dimensão do conhecimento que tanto está presente nos cursos de formação, nos momentos em que se trabalha na reflexão sobre a atividade profissional, como durante o estágio, nos momentos em que se exercita a atividade profissional. [...] A ideia a ser superada, enfim, é a de que o estágio é o espaço reservado à prática, enquanto, na sala de aula se dá conta da teoria (BRASIL, 2009).

Com essa política percebe-se a intenção de produzir uma nova práxis por meio de um novo processo de formação, resultante de uma reestruturação curricular capaz de implantar efetivamente as ideias-chave da nova legislação.

Em 2006, o Conselho Nacional de Educação, depois de muitos debates aprova a Resolução $\mathrm{n}^{\circ} 1$, com as Diretrizes Curriculares Nacionais para o curso de Pedagogia, propondo a este a formação de professores de Educação Infantil e dos anos iniciais do 
ensino fundamental, bem como para o ensino médio na modalidade Normal, onde esse fosse necessário e para educação de jovens e adultos, além da formação de gestores. A referida Resolução estabelece princípios e normas, assim como carga horária para o curso de 3.200 horas de efetivo trabalho acadêmico, das quais, no mínimo 300 horas, devem ser dedicadas ao estágio supervisionado. Considera, também, mais 100 horas de atividades teórico-práticas de aprofundamento em áreas específicas de interesse dos alunos.

Em julho de 2015 novas diretrizes foram homologadas para orientar a formação dos profissionais do magistério da educação básica, nesta perspectiva indagamos: O que estas diretrizes trazem de novo para a formação docente? Qual o impacto no processo formativo?

\section{A nova política de formação de professores: as diretrizes curriculares nacionais para formação inicial e continuada}

Diante da aprovação das Diretrizes Curriculares Nacionais para a formação inicial em nível superior (cursos de licenciatura, curso de formação pedagógica para graduados e curso de segunda licenciatura) e para formação continuada, no dia $1^{\circ}$ de julho de 2015 , indagamos: que novidades o documento traz para a organização curricular dos cursos de formação de professores? Que mudanças efetivamente são propostas para a formação inicial e continuada?

É importante destacar que a formação de profissionais do magistério da educação básica tem se constituído em campo de disputas de concepções, dinâmicas, políticas e currículos. De modo geral, a despeito das diferentes visões, os estudos e pesquisas apontam para a necessidade de se repensar a formação desses profissionais. O que nos remete à necessidade de refletirmos sobre a complexidade do processo de ensinar, enfatizando a importância dos processos formativos superarem o modelo da racionalidade técnica, que historicamente, vem fundamentando os cursos de formação inicial e continuada dos profissionais do magistério da educação básica, para consolidação de uma perspectiva de formação profissional que priorize práticas docentes reflexivas e críticas.

Nesse sentido, considerando a legislação em vigor, com destaque para o PNE/2014 e a deliberação da Comissão Bicameral no sentido de encaminhar diretrizes conjuntas para a formação inicial e continuada dos profissionais do magistério da educação básica, assim como as políticas voltadas para maior organicidade desta formação, as novas DCN aprovadas em $1^{\circ}$ de julho de 2015 apresentam os seguintes considerandos, como aportes e 
concepções fundamentais para a melhoria da formação inicial e continuada e suas dinâmicas formativas:

1. A consolidação das normas nacionais para a formação de profissionais do magistério para a educação básica é indispensável para o projeto nacional da educação brasileira;

2. A concepção sobre conhecimento, educação e ensino é basilar para garantir o projeto da educação nacional, superar a fragmentação das políticas públicas e a desarticulação institucional por meio da instituição do Sistema Nacional de Educação, instituído no bojo de relações de cooperação e colaboração entre entes federados e sistemas educacionais;

3. A igualdade de condições para o acesso e a permanência na escola; a liberdade de aprender, ensinar, pesquisar e divulgar a cultura, o pensamento, a arte e o saber; o pluralismo de ideias e de concepções pedagógicas; o respeito à liberdade e o apreço à tolerância; a valorização do profissional da educação; a gestão democrática do ensino público; a garantia de um padrão de qualidade; a valorização da experiência extraescolar; a vinculação entre a educação escolar, o trabalho e as práticas sociais; o respeito e a valorização da diversidade étnico-racial, entre outros;

4. As instituições educativas nas diferentes etapas (educação infantil, ensino fundamental e ensino médio) e modalidades da educação básica cumprem, sob a legislação vigente, um papel estratégico na formação requerida pelos níveis de ensino cujo eixo de atuação são os projetos pedagógicos;

5. A necessidade de articular as Diretrizes Curriculares Nacionais para a Formação Inicial e Continuada, em Nível Superior, e as Diretrizes Curriculares Nacionais para a Educação Básica;

6. Os princípios que norteiam a base comum nacional para a formação inicial e continuada, tais como: a) sólida formação teórica e interdisciplinar; b) unidade teoria-prática; c) trabalho coletivo e interdisciplinar; d) compromisso social e valorização do profissional da educação; e) gestão democrática; f) avaliação e regulação dos cursos de formação;

7. A articulação entre graduação e pós-graduação e entre pesquisa e extensão como princípio pedagógico essencial ao exercício e aprimoramento do profissional do magistério e da prática educativa;

8. A docência como ação educativa e como processo pedagógico intencional e metódico;

9. O currículo como o conjunto de valores propício à produção e à socialização de significados no espaço social e que contribui para a construção da identidade sociocultural do educando, dos direitos e deveres do cidadão, do respeito ao bem comum e à democracia, às práticas educativas formais e não formais e à orientação para o trabalho;

10. A realidade concreta dos sujeitos que dão vida ao currículo e às instituições de educação básica, sua organização e gestão, os projetos e cursos de formação, devem ser contextualizados no espaço e no tempo e atentos às características das crianças, adolescentes, 
jovens e adultos que justificam e instituem a vida da/e na escola, bem como, possibilitar a compreensão e reflexão sobre as relações entre a vida, o conhecimento, a cultura, o profissional do magistério, o estudante e a instituição;

11. A educação em e para os direitos humanos é um direito fundamental constituindo uma parte do direito à educação e, também, uma mediação para efetivar o conjunto dos direitos humanos reconhecidos pelo Estado brasileiro em seu ordenamento jurídico e pelos países que lutam pelo fortalecimento da democracia;

12. A importância do profissional do magistério e de sua valorização profissional;

13. O trabalho coletivo como dinâmica político-pedagógica que requer planejamento sistemático e integrado.

Em termos de organização curricular e em busca de maior organicidade das políticas de formação dos profissionais do magistério da educação básica, as novas DCN destacam, segundo Dourado (2015, p. 306) que estes processos exigem o repensar e o avançar dos marcos referenciais atuais para a formação inicial e continuada "[...] por meio de ações mais orgânicas entre as políticas e gestão para a educação básica e a educação superior, incluindo a pós-graduação e, nesse contexto, para as políticas direcionadas à valorização dos profissionais da educação ".

Nessa direção as novas DCN em sintonia com o Documento Final da CONAE (2014) basicamente referendam os principais marcos normativos da Política Nacional de Formação de Profissionais do Magistério da Educação Básica, explícitos no do Decreto ${ }^{\circ}$ 6.755/2009, ao apontar como finalidade da política nacional organizar e efetivar, em regime de colaboração entre a União, os Estados, o Distrito Federal e os Municípios, em estreita articulação com os sistemas, redes e instituições de educação básica e superior, a formação dos profissionais do magistério da educação básica. E aponta como princípios básicos da formação inicial e continuada os definidos no artigo $2^{\circ}$ do referido decreto:

I. a formação docente para todas as etapas e modalidades da educação básica como compromisso público de Estado, buscando assegurar o direito das crianças, jovens e adultos à educação de qualidade, construída em bases científicas e técnicas sólidas em consonância com as Diretrizes Curriculares Nacionais para a Educação Básica;

II. a formação dos profissionais do magistério (formadores e estudantes) como compromisso com projeto social, político e ético que contribua para a consolidação de uma nação soberana, democrática, justa, inclusiva e que promova a emancipação dos indivíduos e grupos sociais, atenta ao reconhecimento e à valorização da diversidade e, portanto, contrária a toda forma de discriminação; 
III. a colaboração constante entre os entes federados na consecução dos objetivos da Política Nacional de Formação de Profissionais do Magistério da Educação Básica, articulada entre o Ministério da Educação (MEC), as instituições formadoras e os sistemas e redes de ensino e suas instituições;

IV. a garantia de padrão de qualidade dos cursos de formação de docentes ofertados pelas instituições formadoras;

V. a articulação entre a teoria e a prática no processo de formação docente, fundada no domínio dos conhecimentos científicos e didáticos, contemplando a indissociabilidade entre ensino, pesquisa e extensão;

VI. o reconhecimento das instituições de educação básica como espaços necessários à formação dos profissionais do magistério;

VII. um projeto formativo nas instituições de educação sob uma sólida base teórica e interdisciplinar que reflita a especificidade da formação docente, assegurando organicidade ao trabalho das diferentes unidades que concorrem para essa formação;

VIII. a equidade no acesso à formação inicial e continuada, contribuindo para a redução das desigualdades sociais, regionais e locais;

IX. a articulação entre formação inicial e formação continuada, bem como entre os diferentes níveis e modalidades de educação;

X. a compreensão da formação continuada como componente essencial da profissionalização inspirado nos diferentes saberes e na experiência docente, integrando-a ao cotidiano da instituição educativa, bem como ao projeto pedagógico da instituição de educação básica;

XI. a compreensão dos profissionais do magistério como agentes formativos de cultura e da necessidade de seu acesso permanente às informações, vivência e atualização culturais.

Nessa perspectiva, o art. $3^{\circ} \S 6^{\circ}$ define que o projeto de formação deve ser elaborado e desenvolvido por meio da articulação entre a instituição de educação superior e o sistema de educação básica de forma a contemplar:

I. Sólida formação teórica e interdisciplinar dos profissionais;

II. A inserção dos estudantes de licenciatura nas instituições de educação básica da rede pública de ensino, espaço privilegiado da práxis docente;

III. O contexto educacional da região onde será desenvolvido;

IV. Atividades de socialização e avaliação dos impactos;

V. Aspectos relacionados à ampliação e ao aperfeiçoamento do uso da língua portuguesa e à capacidade comunicativa, oral e escrita, como 
elementos fundamentais da formação dos professores e à aprendizagem de Libras;

VI. Questões socioambientais, éticas, estéticas e relativas a diversidade étnico-racial, de gênero, sexual, religiosa, de faixa geracional e sociocultural como princípios de equidade.

Assim, sugerem uma estrutura curricular que articule uma base nacional comum, para repensar o que e como ensinar sem perder de vista a parte diversificada, pautada na concepção de educação como processo emancipatório e permanente, bem como pelo reconhecimento da especificidade do trabalho docente, que conduz a práxis como expressão da articulação entre teoria e prática e a exigência de que se leve em conta a realidade dos ambientes das instituições educativas da educação básica e da profissão (BRASIL, 2015 ).

Com o objetivo de atentender a essa concepção de articulação entre formação inicial e continuada, as novas DCN definem que o(a) egresso(a) da formação inicial e continuada deverá possuir um repertório de informações e habilidades composto pela pluralidade de conhecimentos teóricos e práticos, resultado do projeto pedagógico e do percurso formativo vivenciado, cuja consolidação virá do seu exercício profissional, fundamentado em princípios de interdisciplinaridade, contextualização, democratização, pertinência e relevância social, ética e sensibilidade afetiva e estética, de modo a lhe permitir: conhecimento da instituição educativa, a pesquisa, a análise e a aplicação dos resultados de investigações de interesse da área educacional e específica; a atuação profissional no ensino, na gestão de processos educativos e na organização e gestão de instituições de educação básica. Assim, o projeto de formação, em articulação com o PDI (Projeto de Desenvolvimento Institucional) e o PPI (Projeto Pedagógico Institucional) deve abranger diferentes características e dimensões da iniciação à docência, entre as quais:

I. estudo do contexto educacional, envolvendo ações nos diferentes espaços escolares, como salas de aula, laboratórios, bibliotecas, espaços recreativos e desportivos, ateliês, secretarias;

II. desenvolvimento de ações que valorizem o trabalho coletivo, interdisciplinar e com intencionalidade pedagógica clara para o ensino e o processo de ensinoaprendizagem;

III. planejamento e execução de atividades nos espaços formativos (instituições de educação básica e de educação superior, agregando outros ambientes culturais, científicos e tecnológicos, físicos e virtuais que ampliem as oportunidades de construção de 
conhecimento), desenvolvidas em níveis crescentes de complexidade em direção à autonomia do estudante em formação;

IV. participação nas atividades de planejamento e no projeto pedagógico da escola, bem como participação nas reuniões pedagógicas e órgãos colegiados;

V. análise do processo pedagógico e de ensino-aprendizagem dos conteúdos específicos e pedagógicos, além das diretrizes e currículos educacionais da educação básica;

I leitura e discussão de referenciais teóricos contemporâneos educacionais e de formação para a compreensão e a apresentação de propostas e dinâmicas didáticopedagógicas;

II cotejamento e análise de conteúdos que balizam e fundamentam as diretrizes curriculares para a educação básica, bem como de conhecimentos específicos e pedagógicos, concepções e dinâmicas didático-pedagógicas, articuladas à prática e à experiência dos professores das escolas de educação básica, seus saberes sobre a escola e sobre a mediação didática dos conteúdos;

III desenvolvimento, execução, acompanhamento e avaliação de projetos educacionais, incluindo o uso de tecnologias educacionais e diferentes recursos e estratégias didático-pedagógicas;

IV sistematização e registro das atividades em portfólio ou recurso equivalente de acompanhamento.

Nesta perspectiva, Zeichener (2001) aponta a necessidade de uma formação reflexiva, que permita, por meio de uma atividade pedagógica, a relação com o conhecimento, considerando a realidade histórica e social do ensino. Assim, na elaboração do projeto pedagógico do curso de formação de profissionais para o magistério da educação básica, deve-se procurar evitar a tradiconal fragmentação dos saberes da docência, e a dicotomia teoria/prática, conforme apontam os estudos de (GÓMEZ, 1992; PEREIRA, 1999), assim como a hierarquização desses diferentes saberes, pois ambos são fundamentais no processo de construção da identidade profissional do professor.

\section{Formação inicial do profissional do magistério da educação básica: o que dizem as nas novas DCN}

As novas DCN apresentam princípios orientadores para uma política de formação dos profissionais do magistério, que devem nortear a organização e a estruturação dos cursos de formação inicial. Neste sentido, estas diretrizes preconizam, no Art. $9^{\circ}$, que os cursos de formação inicial para os profissionais do magistério para a educação básica, em nível superior, devem compreender: 

I. cursos de graduação de licenciatura;
II. cursos de formação pedagógica para graduados não licenciados;
III. cursos de segunda licenciatura.

Nessa direção, as novas DCN, atribuem às instituições formadoras a competência de definir, no seu projeto institucional de formação, as formas de desenvolvimento da formação inicial dos profissionais do magistério da educação básica, articuladas às políticas de valorização do magistério, considerando, que essa formação deverá ser ofertada, preferencialmente, de forma presencial.

No Art. 12, são enunciados os núcleos que deverão contemplar os conhecimentos a ser abordados na formação inicial, respeitando a diversidade nacional e a autonomia pedagógica das instituições. Estes núcleos foram agrapados em três campos temáticos:

I. núcleo de estudos de formação geral, das áreas específicas e interdisciplinares, e do campo educacional, seus fundamentos e metodologias, e das diversas realidades educacionais;

II. núcleo de aprofundamento e diversificação de estudos das áreas de atuação profissional, incluindo os conteúdos específicos e pedagógicos, priorizadas pelo projeto pedagógico das instituições, em sintonia com os sistemas de ensino, que, atendendo às demandas sociais, oportunizará, entre outras possibilidades;

III. núcleo de estudos integradores para enriquecimento curricular.

Os três núcleos da forma como se apresentam devem propiciar a formação do profissional que: educa, investiga, planeja, administra a aprendizagem, avalia, participa da gestão escolar, faz uso da tecnologia da informação, reconhece e respeita a diversidade manifestada pelos alunos, imprime sentido pedagógico às práticas escolares, compartilha os conhecimentos adquiridos em sua prática e leva em conta as características dos alunos e de seu meio social, seus temas e necessidades do mundo contemporâneo e os princípios, prioridades e objetivos do projeto educativo.

O artigo 13 introduz um grau de liberdade na seleção e no ordenamento dos conteúdos, o que é bastante favorável e inovador por meio da garantia de base comum nacional ao estabelecer que:

Os cursos de formação inicial de professores para a educação básica em nível superior, em cursos de licenciatura, organizados em áreas especializadas, por componente curricular ou por campo de conhecimento e/ou interdisciplinar, considerando-se a complexidade e multirreferencialidade dos estudos que os englobam, bem como a formação para o exercício integrado e indissociável da docência na 
educação básica, incluindo o ensino da gestão educacional, e dos processos educativos escolares e não escolares, da produção e difusão do conhecimento científico, tecnológico e educacional, estruturam-se por meio da garantia de base comum nacional das orientações curriculares.

O referido artigo define também no $\S 1^{\circ}$ a carga horária mínima de 3.200 (três mil e duzentas) horas de efetivo trabalho acadêmico, em cursos com duração de, no mínimo, 8 (oito) semestres ou 4 (quatro) anos, compreendendo:

I. 400 (quatrocentas) horas de prática como componente curricular, distribuídas ao longo do processo formativo;

II. 400 (quatrocentas) horas dedicadas ao estágio supervisionado, na área de formação e atuação na educação básica, contemplando também outras áreas específicas, se for o caso, conforme o projeto de curso da instituição;

III. pelo menos 2.200 (duas mil e duzentas) horas dedicadas às atividades formativas estruturadas pelos núcleos definidos nos incisos I e II do artigo 12 desta Resolução, conforme o projeto de curso da instituição;

IV. 200 (duzentas) horas de atividades teórico-práticas de aprofundamento em áreas específicas de interesse dos estudantes, conforme núcleo definido no inciso III do artigo 12 desta Resolução, por meio da iniciação científica, da iniciação à docência, da extensão e da monitoria, entre outras, consoante o projeto de curso da instituição.

Considerando a situação atual, o parágrafo $1^{\circ}$ acima citado prescreve um considerável incremento à carga horária total dos cursos de licenciatura, assim como o $\S 5^{\circ}$ do citado art. 13, com relação ao tempo dedicado às dimensões pedagógicas, quando assegura que "não será inferior à quinta parte da carga horária total".

Essa disposição legal será um dos desafios das instituições formadoras, pois reunir todas essas orientações em uma matriz curricular em 8 semestres, especialmente para os cursos noturnos não é tarefa fácil.

O art. 14 trata dos cursos de formação pedagógica para graduados não licenciados, de caráter emergencial e provisório, ofertados a portadores de diplomas de curso superior formados em cursos relacionados à habilitação pretendida com sólida base de conhecimentos na área estudada, os quais devem ter carga horária mínima ${ }^{6}$ variável de

${ }^{6}$ Conforme art. $14 \S 1^{\text {o }}$ - A definição da carga horária deve respeitar os seguintes princípios: I) quando o curso de formação pedagógica pertencer à mesma área do curso de origem, a carga horária deverá ter, no mínimo, 1.000 (mil) horas; II) quando o curso de formação pedagógica pertencer a uma área diferente da do curso de origem, a carga horária deverá ter, no mínimo, 1.400 (mil e quatrocentas) horas; III) a carga horária do estágio curricular supervisionado é de 300 (trezentas) horas; IV) deverá haver 500 (quinhentas) horas dedicadas às atividades formativas; V) referentes ao inciso I deste parágrafo, estruturadas pelos núcleos definidos nos incisos I e II do artigo 12 desta Resolução, conforme o projeto de curso da instituição; VI) 
1.000 (mil) a 1.400 (mil e quatrocentas) horas de efetivo trabalho acadêmico, dependendo da equivalência entre o curso de origem e a formação pedagógica pretendida.

Considerando-se tratar de cursos para graduados não licenciados, as novas DCN definem prazo máximo de 5(cinco) anos para que o Ministério da Educação, em articulação com os sistemas de ensino e com os fóruns estaduais permanentes de apoio à formação docente, efetive avaliação do desenvolvimento desses cursos, definindo prazo para sua extinção em cada estado da federação.

Outro artigo que merece ser ressaltado é o art. 15, que trata dos cursos de segunda licenciatura, estes deverão ter carga horária variável de 800 (oitocentas) a 1.200 (mil e duzentas) horas, dependendo da equivalência entre a formação original e a nova licenciatura e devem respeitar os seguintes princípios explicitos no $\S 1^{\circ}$ do art. 15 :

I. quando o curso de segunda licenciatura pertencer a mesma área do curso de origem, a carga horária deverá ter, no mínimo, 1.000 (mil) horas;

II. quando o curso de formação pedagógica pertencer a uma área diferente da do curso de origem, a carga horária deverá ter, no mínimo, 1.400 (mil e quatrocentas) horas;

III. a carga horária do estágio curricular supervisionado é de 300 (trezentas) horas.

Em face do exposto, cabe às instituições formadoras de professores durante o processo de formação inicial, garantir a reflexão crítica, a investigação e a unidade teoria/prática, favorecendo elementos básicos para formar um docente questionador, investigador, reflexivo e crítico, para que com essa formação, o professor problematize criticamente a realidade em que atua, adote uma postura ativa no cotidiano da escola e torne-se um profissional capaz de desenvolver um trabalho comprometido em sua atuação profissional.

Sabendo que a formação inicial não é suficiente para atender a complexidade e a dinâmica do processo de ensino e aprendizagem, as novas DCN dedicam o Capítulo VI à formação continuada, alicerçada em conhecimentos e múltiplos saberes, específicos da

deverá haver 900 (novecentas) horas dedicadas às atividades formativas referentes ao inciso II deste parágrafo, estruturadas pelos núcleos definidos nos incisos I e II do artigo 12 desta Resolução, conforme o projeto de curso da instituição; VII) deverá haver 200 (duzentas) horas de atividades teórico-práticas de aprofundamento em áreas específicas de interesse dos alunos, conforme núcleo definido no inciso III do artigo 12, consoante o projeto de curso da instituição. 
ação de ensinar e aprender, na perspectiva de formar professores com habilidades necessárias ao exercício da docência.

\title{
Formação continuada dos profissionais do magistério da educação básica e as DCN
}

A formação de profissionais do magistério para a educação básica, na forma que é concebida e institucionalizada, é indispensável para o projeto nacional da educação brasileira, em seus níveis e modalidades da educação. Neste contexto, avançam no sentido de concepção ampla e valorização, entendida a partir da articulação entre formação inicial, formação continuada, entre outros.

No viés dessa concepção, a formação continuada dos profissionais do magistério da educação básica, se apresenta como conquista social definida em política pública como um direito, a formação para a cidadania e para a emancipação dos cidadãos, concebendo desse modo, a educação como direito e a centralidade do trabalho docente como práxis. Para tanto, propõe a articulação entre formação inicial e continuada, estruturada em um eixo que tem uma base comum nacional e na garantia de institucionalização desse projeto institucional de formação.

Nóvoa (1992) corrobora com importantes considerações acerca da formação de professores e com a necessidade de projeto da profissão docente ao afirmar que:

\begin{abstract}
A formação de professores ocupa um lugar central neste debate, que só se pode travar a partir de uma determinada visão (ou projecto) da profissão docente. É preciso reconhecer as deficiências científicas e a pobreza conceptual dos programas actuais de formação de professores. E situar a nossa reflexão para além das clivagens tradicionais (componente científica versus componente pedagógica, disciplinas teóricas versus disciplinas metodológicas, etc.), sugerindo novas maneiras de pensar a problemática da formação de professores (p.10).
\end{abstract}

Nesse sentido, o Conselho Nacional de Educação vêm envidando esforço para a consolidação dessa política de Formação dos profissionais da educação básica que está institucionalizada a partir da Constituição da República Federativa do Brasil, de1988CF/1988; Lei de Diretrizes e Bases da Educação Nacional, de 20 de dezembro de 1996LDB/1996; EC n53, de 19 de dezembro de 2006, que cria o Fundo de Manutenção e Desenvolvimento da Educação Básica e de Valorização dos Profissionais da Educação 
(Fundeb) em substituição ao Fundef; Lei 12.014/2009; Lei12. 056/2009; Lei $\mathrm{n}^{\circ}$ 12.796/2013, que modificaram a LDB/1996

Considerando a especificidade do tema, faremos uma incursão do aspecto legal a partir da Lei de Diretrizes e Bases/1996 após as modificações recentes em seu Art. 62, § 2º, que preconiza: "A formação continuada e a capacitação dos profissionais de magistério poderão utilizar recursos e tecnologias de educação à distância" (Incluído pela Lei no 12 . 056, de 2009) e prossegue o Parágrafo único, define que: "Garantir-se-á formação continuada para os profissionais a que se refere o caput, no local de trabalho ou em instituições de educação básica e superior, incluindo cursos de educação profissional, cursos superiores de graduação plena ou tecnológicos e de pós-graduação".

Assim, a educação contínuada tem sido institucionalizada em conformidade com concepções que acenam o momento político da época em que esse processo se desenvolve. Desse modo, a formação contínuada significa o processo dinâmico por meio do qual, os professores no exercício de sua prática profissional, através de palestras, seminários, cursos, oficinas ou outras propostas vão adequando sua formação às exigências do ato de ensinar, buscando ensinar, conforme afirmou FREIRE (1983): ultrapassar a visão fragmentada da realidade, possibilitando aos sujeitos envolvidos no processo ensinoaprendizagem a superação do individualismo por meio de ações partilhadas, da liberdade de pensamento e de ações cidadãs que ultrapassem a visão funcionalista da educação que busca a adaptação dos sujeitos ao mundo, sem contestação ou sem resistência à situação vivenciada. A formação contínua possibilita, portanto, o reapetrechamento dos professores, reestruturando e aprofundando conhecimentos adquiridos na formação inicial bem como a produção de novos conhecimentos.

Brzezinski (2015), em palestra proferida no X Seminário Nacional da Associação Nacional pela Formação dos Profissionais da Educação (Anfope), III Simpósio de Formação de Professores do Instituto Federal da Bahia (IFB), ressalta que a formação continuada visa ao desenvolvimento profissional e tece considerações acerca da formação docente:

A formação docente inicial e continuada para a educação básica constitui processo dinâmico e complexo, direcionado à melhoria permanente da qualidade social da educação e à valorização profissional, devendo ser assumida em regime de colaboração pelos entes federados nos respectivos sistemas de ensino e desenvolvida pelas instituições de educação credenciadas. 
Diante desta afirmação, constatamos que as intenções políticas contidas nas Diretrizes Curriculares Nacionais, para a Formação Inicial e Continuada dos Profissionais do Magistério da Educação Básica, para sua concretude, deverá considerar o sistema de redes de ensino, o acompanhamento, a inovação tecnológica, o respeito ao protagonismo do professor, o diálogo e a parceria com atores e instituições competentes e a articulação com o planejamento estratégico do Fórum Estadual Permanente de Apoio à Formação Docente.

Assim posto, o que podemos esperar do que preconiza as diretrizes curriculares nacionais para a formação dos profissionais do magistério da educação básica - Resolução $\mathrm{n}^{\mathrm{o}} 2$ de $1^{\mathrm{o}}$ de julho de 2015 , acerca da política e das práticas na perspectiva da formação dos professores em processos de formação continuada? No mínimo, que oportunize a esses docentes em processo de formação continuada a compreender e a refletir sobre as exigências da profissão docente e sobre as contradições do ato de ensinar e que fundamentalmente esses professores tenham a consciência das implicações do seu fazer na vida dos alunos.

Desse modo, a formação continuada se configura como processo primordial e contínuo que requer uma caminhada investigativa e dialógica, haja vista, os desafios que se apresentam com o advento dos movimentos sociais, políticos e econômicos da atualidade exigindo, do professor, um olhar holístico para a realidade e que favoreça o desenvolvimento de estratégias educativas inovadoras.

Esse paradigma que impõe uma dinâmica nova à prática profissional do professor leva em conta o que define o Art. 16:
A formação continuada compreende dimensões coletivas, organizacionais e profissionais, bem como o repensar do processo pedagógico, dos saberes e valores, e envolve atividades de extensão, grupos de estudos, reuniões pedagógicas, cursos, programas e ações para além da formação mínima exigida ao exercício do magistério na educação básica, tendo como principal finalidade a reflexão sobre a prática educacional e a busca de aperfeiçoamento técnico, pedagógico, ético e político do profissional docente ( BRASIL, 2015).

Nesse sentido, o professor precisa adotar novas práticas educativas visando um aprendizado significativo e dinâmico que dê vida a instituição educativa transformando-a em espaço cultural aberto, propiciando ao aluno a oportunidade de produzir conhecimentos necessários a transformação da comunidade, enfim, da sociedade em que vive. 


\section{Considerações finais}

Ao analisar e refletir acerca das novas diretrizes de formação dos profissionais do magistério da educação básica, aprovadas por meio da Resolução CNE/ CP no 2 de $1^{\circ}$ de julho de 2015, procuramos ressaltar os aspectos mais controvertidos e o que em algumas passagens representam desafios em relação ao estabelecimento de uma política nacional de formação dos profissionais do magistério da educação básica.

Conforme já assinalado, a luta pela garantia de um padrão de qualidade social na formação dos profissionais do magistério deve ser alvo a ser perseguido e deve contar com a interlocução entre as instâncias formadoras e as secretarias de educação, visando desenvolver ações articuladas em prol da defesa da qualidade na formação inicial e continuada dos profisionais da educação. Assim, a definição de políticas que se voltem para a formação dos profissionais do magistério passa pela garantia de padrão de qualidade a ser efetivada por meio da indissociabilidade entre ensino, pesquisa e extensão e pela valorização profissional, devendo ser assumida em regime de colaboração pelos entes federados nos respectivos sistemas de ensino.

Com essa compreensão, a formação dos profissionais do magistério da educação básica, em nível superior, coloca-se como uma meta a ser implementada como política de Estado. Assim, a discussão sobre formação e valorização profissional passa, portanto, pelo resgate das políticas concretas que incluam o questionamento e novos acenos dos atuais marcos de formação incorporando, desse modo, a formação contínuada e a melhoria das condições de trabalho.

Muito do que as novas diretrizes trazem não são novidades para quem trabalha com a formação docente, mas existem desafios ainda não superados incitados pelas diretrizes anteriores, que devem ser enfrentados conjuntamente pelas diversas áreas das licenciaturas e pelas instituições formadoras, a partir de estratégias comuns, dentre elas: articulação entre teoria e prática nas licenciaturas, interdisciplinaridade, a prática como componente curricular; e a inserção das novas tecnologias de informação e comunicação nas salas de aula.

Enfim, para pensar, compreender e refletir acerca do que preconizam as diretrizes curriculares nacionais para a formação dos profissionais do magistério da educação básica e sobre os possíveis impactos decorrentes dessas diretrizes na institucionalização e nas 
práticas curriculares dos referidos cursos, na direção de uma nova concepção de formação docente é decisivo que as instituições formadoras:

a) assumam um posicionamento e um compromisso institucional a favor da formação do profissional do magistério, nos cursos de licenciatura, por meio de uma construção coletiva, envolvendo graduação e pós-graduação e entre pesquisa e extensão como princípio pedagógico essencial ao exercício e aprimoramento do profissional do magistério e da prática educativa;

b) formalizem as relações com a escola pública, a fim de possibilitar a integração necessária na formação do profissional do magistério da educação básica, de modo a vincular teoria e prática desde o inicio do curso, a partir da pesquisa e do efetivo estágio no interior da escola, permitindo a reflexão e o confronto da teoria com a realidade vivenciada.

Com as determinações das DCN, os cursos de formação inicial de professores deverão implementar nos seus currículos, não somente a ampliação da carga horária, mas, sobretudo, a perspectiva atribuída às relações dialógicas entre teoria e prática. Outro aspecto, que merece destaque é a aprendizagem de procedimentos investigativos e de interpretação da realidade, assim como a interdisciplinaridade curricular e o uso competente das tecnologias de Informação e Comunicação (TIC) para o aprimoramento da prática pedagógica e a ampliação da formação cultural dos(as) professores(as) e estudantes. Dessa forma, propõe-se uma atuação coletiva dos futuros professores no espaço escolar, favorecendo trocas reflexivas sobre suas práticas, qualificando a sua atuação e proporcionando um processo contínuo de formação.

Por fim, as DCN salientam a premência de articulação entre instituições formadoras de ensino superior e as instituições escolares de educação básica. Reconhecemos a urgência da existência desse diálogo e da articulação institucional. Entretanto, sabemos da dificuldade em operacionalizar essa parceria, assim, nos parece necessário a busca de alternativas para um diálogo profícuo entre instituições formadoras de professores de nível superior e as instituições de educação básica.

\section{REFERÊNCIAS}

BRASIL. Decreto n ${ }^{0}$ 6.755, de 29 de janeiro de 2009. Institui a Política Nacional de Formação de Profissionais do Magistério da Educação Básica, disciplina a atuação da Coordenação de Aperfeiçoamento de Pessoal de Nível Superior, e dá outras providências. Brasília/DF: MEC, 2009a. 
BRASIL. Plano Nacional de Educação. Lei no 13.005/2014. Presidência da República, 2014.

BRASIL. Conselho Nacional de Educação. Define as Diretrizes Curriculares Nacionais para a formação inicial em nível superior (cursos de licenciatura, cursos de formação pedagógica para graduados e cursos de segunda licenciatura) e para a formação continuada. Resolução CNE/CP n. 02/2015, de $1^{\text {o }}$ de julho de 2015. Brasília, Diário Oficial [da] República Federativa do Brasil, seção 1, n. 124, p. 8-12, 02 de julho de 2015.

BRASIL. Conselho Nacional de Educação. Diretrizes Curriculares Nacionais para a Formação Inicial e Continuada dos Profissionais do Magistério da Educação Básica. Parecer $n^{\circ}$ 2/2015, de 9 de junho de 2015. Brasília, Diário Oficial [da] República Federativa do Brasil, Seção 1, Pág. 13, de 25 de junho de 2015.

BRASIL. Conselho Nacional de Educação. Resolução CNE/CEB nº 6, de 20 de setembro de 2012, dispõe sobre as Diretrizes Curriculares Nacionais para a Educação Profissional Técnica de Nível Médio. Brasília, Diário Oficial [da] República Federativa do Brasil, 21 de setembro de 2012, Seção 1, p. 22.

BRASIL. Conselho Nacional de Educação. Resolução CNE/CEB nº 4, de 13 de julho de 2010 dispõe sobre as Diretrizes Curriculares Nacionais Gerais para a Educação Básica. Brasília, Diário Oficial [da] República Federativa do Brasil, 14 de julho de 2010, Seção 1, p. 824, 2010.

\section{BRASIL. Ministério da Educação. Documento Final da Conferência Nacional de}

Educação (Conae). Brasília, MEC, 2010. Disponível em

<http://conae.mec.gov.br/images/stories/pdf/pdf/documetos/documento_final_sl.pdf>. Acesso em: 10 jan. 2016.

BRASIL. Ministério da Educação. Documento Final da Conferência Nacional de Educação (Conae). Brasília, MEC, 2014. Disponível em <http://fne.mec.gov.br/images/doc/DocumentoFinal.pdf>. Acesso em: 10 jan. 2016.

BRASIL, Constituição (1988). Emenda Constitucional no 53, de 19 de dezembro de 2006. Dá nova redação aos arts. $7^{\circ}, 23,30,206,208,211$ e 212 da Constituição Federal e ao art. 60 do Ato das Disposições Constitucionais Transitórias. Diário Oficial da União - Seção 2 Edição nr 247 de 27/12/2006, p. 15.

BRASIL, Lei $\mathrm{n}^{\circ}$ 12.796, de 4 de abril de 2013. Altera a Lei no 9.394, de 20 de dezembro de 1996, que estabelece as diretrizes e bases da educação nacional, para dispor sobre a formação dos profissionais da educação e dar outras providências. Diário Oficial da União - Seção 1 Edição nr 65 de 05/04/2013, p.1.

BRASIL, Lei $n^{\circ} 12.056$, de 13 de outubro de 2009. Acrescenta parágrafos ao art. 62 da Lei $\mathrm{n}^{\circ}$ 9.394, de 20 de dezembro de 1996, que estabelece as diretrizes e bases da educação nacional. Diário Oficial da União - Seção 1 Edição nr 196 de 14/10/2009 
BRASIL. Lei ${ }^{\circ}$ 12.014, de 6 de agosto de 2009. Altera o art. 61 da Lei no 9.394, de 20 de dezembro de 1996, com a finalidade de discriminar as categorias de trabalhadores que se devem considerar profissionais da educação. Diário Oficial da União - Seção 1 Edição nr 150 de 07/08/2009.

DOURADO, L. F.; PARO, V. H. (orgs.). Políticas públicas \& educação básica. São Paulo: Xamã, 2001.

DOURADO, L. F. Diretrizes curriculares nacionais para a formação inicial e continuada dos profissionais do magistério da educação básica: concepções e desafios. Educação e Sociedade, Campinas v. 36 nº 131, p. 299-324, abr.- jun., 2015.

BRZEZINSKI, I. Diretrizes para a formação docente: desafios e perspectivas. X Seminário Nacional da Anfope e III Simpósio de Formação de Professores do IFB 2015.

GOMEZ, A. I. P. As funções sociais da escola: da reprodução à reconstrução crítica do conhecimento e da experiência. In: SACRISTÀN, J. G. \& GOMEZ, A. I. P. Compreender e transformar o ensino. Porto Alegre: Artmed, 2000.

NÓVOA, A. Formação de professores e profissão docente. In: NÓVOA, A. (Coord.). Os professores e sua formação. Lisboa: Dom Quixote, 1992.

PEREIRA, J. Formação de profissionais da Educação. Revista Educação e sociedade, Campinas, nº 68, 2a edição, 1999.

ZEICHENER, K. M. A formação reflexiva de professores: ideias e práticas. Lisboa: Educar, 2001.

\section{Como referenciar este artigo}

HONÓRIO, Mirtes Gonçalves et al. As novas diretrizes curriculares nacionais para formação inicial e continuada de professores da educação básica: entre recorrências e novas inquietações. Revista Ibero-Americana de Estudos em Educação, Araraquara, v. 12, n. 3, p. 1736-1755, jul-set/2017. Disponível em: <http://dx.doi.org/10.21723/riaee.v12.n.3.2017.8532>. E-ISSN: 1982-5587.

Submetido em: 26/04/2016

Aprovado em: 16/06/2017 